\title{
Aftercare Service Development for Children in Residential Treatment
}

\author{
Neil B. Guterman \\ University of Michigan \\ Vanessa G. Hodges \\ University of Washingtom \\ Betty J. Blythe \\ University of Pittsburgh \\ Denise E. Bronson \\ State University of New York, Buffalo
}

\begin{abstract}
Increasingly, aftercare services for children returning home from residential treatment are recognized as vital to maintain a child's gains. However, to date, specific knowledge about effective aftercare services, as well as the actual delivery of such services continue to require development. This paper describes an empirically-based, concrete aftercare program that addresses these concerns.
\end{abstract}

Aftercare services for children in residential treatment are receiving increasing attention from both practitioners and researchers in the field (Jensen \& Whittaker, 1987; Guterman \& Blythe, 1986; Jensen, Hawkins \& Catalano, 1986; Kadushin, 1980). Much of this attention is due to the consistent findings of outcome studies in the field, indicating that, "success in residential care, however defined, is largely a function of the supports available in the post-treatment community environment and has much less to do with either presenting problems or type of treatment offered" (Whittaker, 1987). These studies suggest that although emotionally-disturbed children can make considerable gains while in residence, they are often likely to return to high-risk situations upon discharge. Unless provided with effective post-discharge support, these gains may be jeopardized (Whittaker \& Pecora, 1984; Allerhand, Weber \& Haug, 1966; Taylor \& Alpert, 1973; Nelson, Singer \& Johnson, 1978). Aftercare services promote permanency planning by offering support

Address requests for reprints to Neil B. Guterman, School of Social Work, University of Michigan, Ann Arbor, MI 48104. 
and services to families to help maintain the child in the home. Regular and consistent contact from the residential staff is essential in helping to ease the transition and coordinate community services for the family. Initial findings suggest that aftercare services are effective in maintaining the progress made in residential treatment (Van Hagen, 1982).

These empirical findings merely underscore a greater shift occurring recently in residential treatment toward an ecologically-based model of practice (Whittaker, 1987; Guterman \& Blythe, 1986). This model points to the benefits of engaging (rather than separating the child from) the elements of the child's natural ecological context on behalf of the child's mental health. Such elements may include the child's peers, neighborhood, educational system, and, perhaps most importantly, the family. Equally important, this model points to creating a continuity of care across childcare environments; in this case, from family to residential treatment and back. In this context, then, aftercare service development can be seen as one stage of ecologically-modelled residential treatment services, aimed at prevention of further out-of-home placements, as well as at reducing the amount of time a child may spend out-of-home.

Despite both the strong clinical (and fiscal) attractiveness of aftercare, however, existing aftercare services in most residential centers continue to remain sorely undeveloped and unspecified in targeting needs that assure the success of residential treatment. This paper reviews the current state of aftercare services for children in residential treatment centers, and describes an innovative, empirically-developed, extended aftercare program. This program was developed collaboratively by researchers and practitioners at Methodist Children's Village, a residential treatment center serving severely emotionally disturbed children, ages $8-13$, in the greater Detroit area.

\section{The Current State of Aftercare Services in Residential Treatment}

Results of a national study of residential treatment facilities reported by Mayer, Richman, \& Balcerzak (1977), indicated that $85 \%$ of the agencies then surveyed claimed to provide some form of aftercare. However, a closer look revealed that service characteristics of aftercare typically consisted of no more than the following: 1) a post-discharge placement decision; 2) general educational plans for the child; and 3) minimal service provisions to the family, typically one to two home visits within six months of discharge.

Prior to initiating the present pilot program, more recent findings from a follow-up study conducted at Methodist Children's Village 
typified these aftercare needs (Goodman \& Blythe, 1985). Reflecting aftercare service provisions similar to those reported by Mayer and his colleagues, data from this study indicated that a great majority of the discharged cases from 1981 to 1983 received no aftercare visits from agency staff. Of those families receiving aftercare support, the average level of services totaled 1 to 2 home visits and/or 1.5 phone calls from the caseworker after discharge. Regarding the need and desire for aftercare services, this follow-up study revealed that families not provided with aftercare spontaneously indicated a desire for aftercare services more frequently than any other service. Similarly, the families receiving some aftercare stated that they would have preferred an increase in aftercare more than any other type of service.

To date, little is known with regard to what specifically characterizes effective aftercare intervention for children returning to their homes. One study describes a program of aftercare services consisting of biweekly visits over a six-month period that addressed concrete issues, supported the parenting role, and provided resources in assisting the family to link up with local support and school personnel (Van Hagen, 1982). This study reports significant outcome differences in comparing extended aftercare families with families not receiving aftercare on a number of parenting and child behavior indices. Serious design problems and a lack of specification surrounding the services delivered not withstanding, this appears to be the only available study suggesting the effectiveness of aftercare in residential treatment for children. A second study reports in descriptive fashion an aftercare program involving three workers on behalf of the child and family - a family social worker, an aftercare teacher, and a community services and resources worker (Harding, Bellew, \& Penwell, 1978). Effectiveness was not examined in this study.

Finally, reviews of related studies, as well as discussions with practitioners of selected residential treatment centers nationwide have been similarly suggestive of aftercare treatment needs in the areas of: 1) parenting skills, 2) community support linkage, 3) school linkage, and 4) structuring leisure time and handling peer relationships (Jensen, Hawkins, \& Catalano, 1987; Jensen \& Whittaker, 1987). Yet scant information exists to date describing specific helpful interventions that may address these aftercare domains. Realizing both the need for aftercare services as well as the lack of specific knowledge regarding how particular aftercare needs should be addressed clinically, the authors designed and developed a well-specified extended aftercare service package collaboratively with practitioners at Methodist Children's Village. 


\section{Methodology}

\section{Demographics}

All 14 of the cases that have been involved in the aftercare study are boys, with an average length of residence at the agency of approximately 18 months. They range in age from 8 to 13 years old. Racial composition of the children in the group is 43 percent black and 57 percent white. Regarding their placement at the agency, 50 percent of the boys were voluntarily placed in residence by their parents, while 50 percent were court-ordered placements, usually involving charges of abuse and/or neglect. Typical presenting problems include poor peer relationships, aggressiveness, stealing, firesetting, and depression. All children receiving services returned to their natural families. ${ }^{1}$

\section{Developmental Research Methodology}

New developmental (or "design and development") research techniques were relied on to build an empirically-grounded package of services (Thomas, 1984). This model of applied research differs from other models in that the outcome of the research process is an intervention package instead of knowledge or information. The critical steps of this research model require systematic retrieval of theoretical, empirical, and clinical information from which to: 1) delineate the scope and nature of a social need or problem;2) design a blueprint intervention anticipated to optimally address the need or problem; and 3) develop the blueprint into a fully elaborated real world intervention package through a careful series of pilot tests, re-designs, and re-tests, based on empirical and clinical feedback and analysis.

During the pilot test phase of the developmental research model, systematic replication of the intervention components using single-system methodology allows the researcher to continuously monitor whether the desired effects are obtained. When the results are favorable the intervention component can be replicated with another case. If the results indicate no change or a worsening of the problem the intervention procedure can be modified and retested, or abandoned for some entirely different strategy. This continues until each part of the treatment program has been tested across several cases and shown to have general applicability. The intervention program will undergo full-scale evaluation only after each component has been systematically replicated, ${ }^{2}$

The completed aftercare program is described below and data are presented from an analysis of treatment goals collected from family contracts. The goal analysis provided information identifying major areas of concern for parents and the types of services they needed to maintain the child in the home. Each family contract was evaluated and goals were categorized into three major

Discharged children from this agency going to foster or adoptive homes receive supportive services through a separate department of the agency.

${ }^{2}$ For a more detaled discussion of developmental research methodology, refex to Thomas, E.J. (1984). Designing Interventions for the Helping Professions. 
treatment components: parent training, social support linkage, and school linkage and liaisoning. Goals were assigned to categories based on two criteria: 1) who was primarily responsible for achieving the goal, 2) what outside agencies were involved in goal attainment. Each goal was rated by two independent judges. Interrater reliability using this categorization was $89.5 \%$, using the agreements over agreements plus disagreements method.

\section{Characteristics of the Aftercare Services Program: Current Findings ${ }^{3}$}

\section{Program Profile}

The specified aftercare program objective is to facilitate an optimal stabilization for the child in the natural family, once the child has been discharged to home. If effective, aftercare services should protect the gains the child made in residence as well as reduce the likelihood of further out of home placements for the child.

As aftercare services primarily address these transitional objectives, they are anticipated to last between 3 and 6 months, consisting of weekly 1 to $1-1 / 2$ hour meetings. Some cases have required services beyond 6 months, though none have lasted longer than 8 months. The short-term, transitional nature of the aftercare services are emphasized to the family from the outset. Services tend to focus on providing family skills training, on enhancing their problem-solving abilities, and on teaching them to rely on longer-term local support resources. These all promote a family's ability to self-reliantly cope with stressors and problems that arise. If the assessment of the family indicates a need for more intensive longer-term therapeutic work, referral is made to local treatment programs, and support is provided in making contacts to those programs. Aftercare workers do not engage in intensive "relationship" forms of therapy with family members or with the child since the services must be short-term and transitional.

Aftercare services are delivered in the family's home. Although this is somewhat more costly and time consuming, and may carry some potential risk, the treatment advantages for aftercare cases are great. Home sessions concretely state to the family that they must focus intensively on their immediate environment and make things work out in the home now that the child is living there full time. In-home services provide the worker with a prime opportunity to assess and train skills in the environment in which they will be used. As an example, it becomes

${ }^{3}$ The full intervention program is described in greater detail in Blythe, B.J., Hodges, V.G., \& Guterman, N.B. (1988). Extended aftercare services for children leaving residential treatment: A procedural manual. 
easier to teach a parent "time-out" procedures for handling a child's misbehavior if the worker can directly see and work with the home ecology. The worker can more quickly spot an appropriate time-out location (where the child is not near a T.V. or toys), and role play with the family a hypothetical time-out situation. Further, the worker gains a more in-depth assessment of problem behaviors and of the very real stresses with which a family must cope than would be possible in the office. On numerous occasions, workers have had the golden opportunity of walking in the door when a primary problem area had just erupted. This facilitates "live" skills training for the child and family.

\section{Case Management}

Case management activities by the aftercare worker include referral, contracting with the family, and termination. Referral activities introduce the aftercare worker to the particular needs of each child and family. A formalized assessment procedure includes a review of the case history, a parent skills assessment instrument, a social support assessment instrument, and a series of consultations with the child and family's entire residential treatment team. Consultations highlight areas of progress, ongoing problems, and projected prognosis. Potential treatment goals for the family are developed from this information which later assists the worker in designing an aftercare service contract with the family.

Prior to discharging of the child from residential treatment, a minimum of two meetings with the family are arranged to introduce the aftercare worker to the family and to set an initial service contract. Contracts are essential in that they structure and individualize services for the family. Moreover, they prioritize goals and specify who is responsible for what efforts in achieving each treatment goal, insuring that both the worker and the family stay on track in making good faith efforts toward achieving aftercare goals. Contracts reduce potential conflicts and frustrations later if progress is not made, and communicate to the family and child that the worker is a partner in providing for the welfare of the child in the home. They also assist the family in thinking about problem areas and how to address them before they get out of hand. Contracts are renegotiated on a monthly basis to assure that services are targeted appropriately. Contract goals are worded in realistic, attainable, and specific terms so that progress can be objectively measured, interventions can be monitored for potential effectiveness, and families can focus on positive outcomes and realize them when they are achieved. Contracts are time limited, emphasizing to the family the 
importance of making gains in the short but crucial transition phase of aftercare.

Termination decisions are based on the family's progress toward their aftercare treatment goals. During contract renegotiation sessions, expectations about termination dates are set, based on the review of progress made and the assessment of work remaining. As the termination date nears, aftercare workers taper direct services by decreasing the number of visits with the family or by decreasing meeting content and length. At this time, workers encourage families to rely more heavily on local support systems, such as the school, extended family, or an outpatient therapist. At termination, workers review the family's progress on the original aftercare goals and the progress made on them. This serves to provide families with a realistic sense of their gains, as well as to provide closure to the services. Finally, potential and/or ongoing problem areas are noted, and the family's plans to address them are reviewed.

\section{Parent Training/Child Management}

Though families often make some gains in parenting skills while the child is in residence, they typically show greater interest in learning or improving these skills when the child returns home full time. A child's return tests the family's ability to handle parenting under greater stress and on a permanent basis. An analysis of service contract goals revealed that all 14 aftercare cases specified some form of parent training/child management treatment goals. In fact, $50 \%$ of all contracted treatment goals were categorized as parent training or child management.

When parent training/child management issues were targeted for change, skills training most frequently addressed the following areas: stating rules and consequences clearly, following through by enforcing those rules consistently, using effective reinforcers to modify problems behaviors, providing positive attention to the child when his/her behavior is appropriate, and learning family communication skills. This training has addressed such treatment goals as structuring a child's daily routine, reducing a child's back talk, improving a child's ability to follow directions, and reducing a child's wandering behavior. Additionally, aftercare workers have provided families with realistic expectations about normal child development and behavior, since parents often become increasingly unrealistic in their expectations when under stress. Families have also required preparation and direct emotional support when the child leaves the "honeymoon" period and begins to test whether the parents will continue to work to make the return home a permanent arrangement. 


\section{Social Support Linkage}

Families with emotionally disturbed children often are socially isolated, and have not developed skills to appropriately seek necessary support. Their needs for social support increase upon the child's return home. The child's return proves a major stressor on the whole family, both in terms of emotional and material resources. As family stress increases while the residential center begins to withdraw its support, families must develop effective and self-sustaining locally-based support networks. In 11 of the 14 aftercare cases, treatment goals directly addressed social support needs. In fact, 23.7 percent of all contracted goals targeted some social support needs.

After a family's greatest social support needs are prioritized based on a formalized assessment at referral, workers and families jointly determine the optimal resources to address those needs. Goals are then set up to initiate or improve linkages with those resources. Linkage to both formal and informal support resources have proven helpful, depending on the particular need identified. For example, goals have been successfully established to increase a family's contacts with their extended family for assistance in providing respite care for the child, as well as to link families with local therapeutic resources. Often, families need assistance in learning assertiveness skills that will enable them to obtain the appropriate information or service. They may also require information about intake procedures, cost, or transportation to organizations to facilitate linkages. Because it is most difficult to link families to new formal support resources, such as a local outpatient agency, or Big Brothers, workers have found it helpful to initiate such linkages prior to the child's discharge, when the family is under somewhat less stress. Finally, aftercare workers must serve as a liaison by providing advice to both the family and agency about working with one another. Explicitly arranged agreements among the aftercare worker, other support resources, and the family that specify who is responsible for providing services for particular aftercare goals have proven helpful in reducing misunderstandings and in coordinating services and resources.

\section{School Linkage and Liaisoning}

Entry or reentry into the local school district proves to be a major test of the child's ability to function with a new set of peers, a new teacher, and an unfamiliar structured environment. Taken in the context of a family who is learning to function on a daily basis again, school often proves to be the domain where a child first has adjustment problems. Direct intervention by aftercare workers, as specified on service contracts, was indicated in 10 of 14 cases, while services were handled 
entirely by local school districts in the remaining cases. Of all aftercare goals, $14.5 \%$ were categorized as school related.

Careful aftercare liaison work with the local school can prevent a downward spiral toward another out-of-home placement for the child. By providing advocacy for the family and detailed information regarding the child's special characteristics in individual educational planning meetings and through regular, periodic updates with the appropriate personnel, the school can more readily respond directly to the child's needs. Workers help the child and family anticipate what the school placement will be like by speaking with school personnel and conveying realistic information to families, as well as by arranging in-person introductions with the parents, child, teacher, and school social worker.

By coordinating treatment and educational planning with the family and aftercare worker, a greater consistency of behavioral expectations between the home and school ecologies can be effected. Additionally, the aftercare worker works with both the family and the school system in a planful way to prepare them for potential crisis situations before they occur, thereby reducing stress and the likely perceptions that an out-ofcontrol situation can only be solved by another out-of-home placement. Finally, workers teach the families problem-solving skills to address minor school issues on behalf of the child before they become larger issues.

\section{Other Common Need Areas}

The remaining $11.8 \%$ of the contracted goals did not clearly fall in any one category. These goals primarily included treatment efforts aimed at improving sibling or peer relationships, or addressed the parents' individual problems which threatened the child's stability at home, such as reducing marital strife. Combined with the above treatment efforts in parent management, direct social skills training (such as role playing with the child appropriate ways of initiating friendships initiation or asking for help) can prevent or minimize potential neighbor, sibling, and school problems.

\section{Crisis Intervention}

Although instances of crisis could not be categorized using service contracts, 9 of the 14 aftercare cases encountered at least one crisis situation. Aftercare crises are defined as situations which seriously threaten the child's placement at home. The added stress of having the child at home full time combined with the recency of the child's return contributes to the large number of crisis situations. Not surprisingly, most of the crisis situations observed occurred within the first 8 weeks of 
the child's return home. Examples of crises encountered include the child's permanent expulsion from school, out-of-control behavior by the child, death of one parent due to an extended illness, as well as indication of child abuse by one of the caretakers.

By directly assisting the family to effectively cope with and solve these crises, aftercare services should help improve the child's chances of remaining at home, and assist the family in learning skills to improve the stability of the family. Therefore, crisis intervention procedures are initiated prior to a crisis, usually in the second or third visit. Parents are informed that procedures exist to help them manage unexpected problem situations. These procedures involve contacting the aftercare worker directly or an identified resource that can assist with the crisis. This provides the family with a preplanned and rational response to help reduce the stress if and when a crisis occurs. When a crisis arises, workers construct a "mini-contract" with the family which structures a planful response for resolving or coping with the crisis. Like service contracts, a goal is constructed to address the problem and responsibilities of all parties are specified. Local support resources are drawn upon particularly heavily during crises, for example, to provide respite care for a child, or transportation to a hospital. Contact by the worker may be increased, either by a greater frequency of phone calls or by a greater number of visits. When the mini-contract goal is attained, and the crisis resolved or adequately managed, service efforts return to earlier treatment goals.

\section{Early Indicators of Effectiveness}

The components of the aftercare treatment program presented here have been tested, redesigned, and replicated with 14 families. In terms of the developmental research model, the design and development phases have been completed. At this stage, effectiveness data consist of singlecase studies pertaining to various components of the program. As a result, conclusions at this point are tentative. The next step is to evaluate the aftercare package using traditional program evaluation methods.

A number of preliminary indications, however, suggest the importance of aftercare services to families receiving such services. For example, an analysis of behaviorally and clinically measured progress on aftercare treatment goals (such as rating how often a child follows a parent's directions) has indicated mostly positive trends occurring while the child is in the home. These trends are in direct contrast with results reported in the classic studies of families not receiving extended aftercare support, where children show deterioration of gains rather that continued improvement (Allerhand et al., 1966; Taylor \& Alpert, 1973; Nelson et al., 1978). 
A brief client satisfaction questionnaire was developed to measure the level of satisfaction families had with the aftercare service. One month following termination from aftercare, each family was contacted by phone and invited to participate in the satisfaction survey. Seventy-one percent of the families receiving aftercare services participated. Parents reported that they especially liked the contract and the fact that the goals were jointly developed by the family and reflected the individual needs of the child and family. Support, knowledge of community services, and flexibility were identified as the most helpful aspects of the aftercare worker. Parents indicated that the aftercare intervention helped improve communication between the child and parent and helped them to deal with day-to-day problems.

Finally, an analysis of the cost of aftercare to these 14 cases indicates services delivered at 7 percent the per diem cost of residential services. Another residential treatment agency contacted by this research team which already provides extended aftercare as part of their regular residential program indicated a cost of aftercare at approximately onefourth of their residential per diem (Harris, 1985). Nonempirical information suggests that extended aftercare can shorten time in residential treatment (Harding, Bellew, \& Penwell, 1978) or prevent further placements. If, indeed, extended aftercare reduces time out-ofhome, then aftercare services will prove significantly cost-effective to the public.

Clearly, the next steps require further rigorous examination of such questions as overall clinical effectiveness, cost-effectiveness, as well as the relative clinical effectiveness of each component. These will assess to what degree these promising preliminary results are valid, and whether aftercare services achieve stated objectives: namely, to safeguard the gains made by a child and his or her family while involved in residential treatment, and to reduce the likelihood of additional out-of-home placements.

\section{References}

Allerhand, M. E., Weber, R. E., \& Haug, M. (1966). Adaptation and adaptability: The bellefaire follow-up study. New York: Child Welfare League of America.

Blythe, B. J., Bronson, D. E., Guterman, N. B., \& Hodges, V. G. (1987). Methodological issues in developmental research: A case example. Ann Arbor, Michigan: University of Michigan, in preparation.

Blythe, B. J., Hodges, V. G., \& Guterman, N. B. (1988). Extended aftercare services for children leaving residential treatment: A procedural manual. Seattle: University of Washington,

Garbarino, J. (1982). Children and families in the social environment. New York: Aldine. 
Goodman, D. R., \& Blythe, B. J. (1985). A follow-up report of children discharged from Methodist Children's Home Society between 1981-1983. Detroit: Methodist Children's Home Society.

Guterman, N. B., \& Blythe, B. J. (1986). Toward ecologically based intervention in residential treatment for children. Social Service Review, 60 (4), 633-643.

Harding, E. H., Bellew, J., \& Penwell, Larry W. (1978). Project Aftercare: Followup to residential treatment. Behavioral Disorders, 4, 13-22.

Harris, D. (1985). Personal communication. Pepperlike, Ohio: Beachbrook Residential Treatment Center.

Hartman, A., \& Laird, J. (1983). Family-centered social work practice. New York: The Free Press, 3-22.

Hodges, V.G., \& Blythe, B. J. (1987). The use of home visits in providing services to children and families. Ann Arbor: University of Michigan, in preparation.

Jensen, J. M., Hawkins, J. D., \& Catalano, R. F. (1986). Social support in aftercare services for troubled youth. Children and Youth Services Review, 8(4), 323-347.

Jensen, J. M., \& Whittaker, J. K. (1987). Parental involvement in children's residential treatment: From preplacement to aftercare. Children and Youth Services Review, 9 (2), $81-100$.

Kadushin, A. (1980). Child welfare services. New York: MacMillan, 605-606.

Mayer, M. F., Richman, L.H., \& Balcerzak, E. A. (1977). Group care of children: Crossroads and transitions. New York: Child Welfare League of America.

Nelson, R. H., Singer, M. J., \& Johnson, L. O. (1978). The application of a residential treatment evaluation model. Child Care Quarterly, 7 (2), 164-173.

Taylor, D. A., \& Alpert, S. W. (1973). Continuity and support following residential treatment. New York: Child Welfare League of America.

Thomas, E. J. (1984). Designing interventions for the helping professions. Beverly Hills, CA: Sage, $139-214$.

Van Hagen, J. (1982). Aftercare as a distinct and necessary treatment phase: Results of the St. Vincent's aftercare study. Residential Group Care and Treatment, 1 (2), 19-29.

Whittaker, J. K. (1987). Group care for children. In A Minahan (Ed.), Encyclopedia of Social Work, vol. 1,18 th Edition. Silver Spring, MD: National Association of Social Workers, $672-682$.

Whittaker, J. K., \& Pecora, P. J. (1984). A research agenda for residential child care. In T. Philpot (Ed.), Group care practice: The challenge of the next decade. Sutton, Surrey, U.K.: Business Press International, 71 -87 . 